Mens

revue d'histoire intellectuelle de l'Amérique française

Louis-Antoine Dessaulles. Discours sur la tolérance suivi du mémoire de l'évêque Bourget. Présentation et notes par Adrien Thério. Montréal, XYZ Éditeur, 2002. 103 p. (Coll. " Documents »)

\title{
Roberto Perin
}

Volume 4, numéro 1, automne 2003

URI : https://id.erudit.org/iderudit/1024631ar

DOI : https://doi.org/10.7202/1024631ar

Aller au sommaire du numéro

Éditeur(s)

Centre de recherche en civilisation canadienne-française

ISSN

1492-8647 (imprimé)

1927-9299 (numérique)

Découvrir la revue

Citer ce compte rendu

Perin, R. (2003). Compte rendu de [Louis-Antoine Dessaulles. Discours sur la tolérance suivi du mémoire de l'évêque Bourget. Présentation et notes par Adrien Thério. Montréal, XYZ Éditeur, 2002. 103 p. (Coll. « Documents »)]. Mens, 4(1), 104-111. https://doi.org/10.7202/1024631ar 
Louis-Antoine Dessaulles. Discours sur la tolérance suivi du mémoire de l'évêque Bourget. Présentation et notes par Adrien Thério. Montréal, XYZ Éditeur, 2002. 103 pages. (Coll. « Documents »).

Pour marquer le vingt-cinquième anniversaire de l'Institut canadien de Montréal, son ancien président, Louis-Antoine Dessaulles, prononce une conférence sur la tolérance. Elle sera publiée dans l'Annuaire de l'Institut canadien pour 1868 que l'évêque Ignace Bourget de Montréal va exploiter dans un long mémoire au Saint-Siège pour demander la condamnation de l'Institut. Rome ne tardera pas à mettre la publication à l'Index des Livres interdits. L'évêque profitera de cet acte officiel pour condamner l'Institut, ce qui va provoquer la tristement célèbre Affaire Guibord. Cette cause qu'instituent en 1869 les confrères du défunt imprimeur, Joseph Guibord, gravit tous les échelons de l'appareil judiciaire jusqu'au Comité judiciaire du Conseil privé à Londres. Celui-ci statue en 1874 que, contrairement aux directives de l'autorité religieuse, Guibord doit être inhumé dans le cimetière catholique. Au cœur d'une importante crise intellectuelle et morale qui a secoué le Québec au dix-neuvième siècle, ces deux documents - la conférence de L.-A. Dessaulles et le mémoire d'Ignace Bourget - sont publiés dans une édition qui comprend une courte présentation et des notes explicatives du littérateur Adrien Thério.

Sous les grands traits qu'en esquisse Thério, cet affrontement entre le pamphlétaire et l'évêque apparaît comme une lutte épique du Bien contre le Mal. L.-A. Dessaulles en est le héros. Le neveu du grand Louis-Joseph Papineau, qui le considère comme son alter ego, est un savant: "il a passé sa vie à lire les grands écrivains, à les étudier» (pp. 14, 27). Possédant un esprit ouvert sur le monde, qu'ont raffermi ses voyages 
aux États-Unis et en Europe occidentale, il livre un combat implacable à la Réaction. L'Église catholique est partie intégrante de cet axe du Mal. Sous le joug de papes autoritaires, tels que Grégoire XVI et Pie IX, elle veut garder l'homme dans l'obscurité politique, morale et intellectuelle du passé.

Son suppôt au Québec est l'évêque Bourget. Celui-ci regarde Montréal comme « un fief qui lui [appartient] » (p. 15), mais il arrive mal à contrôler l'Institut qui réunit, dans les années 1850, «les grands intellectuels opposés à son intégrisme » (p. 26). L'évêque entend donc le "dépouiller» (p. 17) de sa bibliothèque parce qu'elle renfermerait de mauvais livres qu'il refuse pourtant d'identifier. Il repousse toute tentative d'accommodement que formuleront par la suite certains membres. Aux yeux de Thério, cette question n'est finalement "qu'un prétexte » dont veut se servir l'évêque "pour se débarrasser » (p. 25) d'un dangereux rival. Car l'Institut rêve, dans les années 1860, de mettre sur pied une université laïque en opposition à l'institution catholique qu'Ignace Bourget pressera vainement le Saint-Siège de lui accorder pendant les derniers quinze ans de son épiscopat. L.-A. Dessaulles apparait ainsi comme un précurseur du Québec laïc.

Le présentateur fait preuve, cependant, d'une connaissance plutôt approximative de la période. Il affirme que le cardinal Antonelli fut premier ministre des États pontificaux (p. 18), alors que celui-ci n'a occupé d'autre charge que celle de Secrétaire d'État. Aussi Thério semble-t-il ignorer que «la grande fête » qui a lieu à Rome en 1870 «à l'occasion de la proclamation de l'infaillibilité pontificale » (p. 23) est bien le Premier Concile du Vatican et non un simple synode (p. 99). Il est en outre permis de se demander si l'auteur a vraiment compris les enjeux du conflit lorsqu'il écrit : "L'évêque ne pouvait s'opposer à ce que l'Institut accepte des catholiques de langue anglaise qui s'exprimaient aussi bien en français 
qu'en anglais. Il fallait donc trouver une autre question pour [le] combattre » (p. 15). Mais il n'est jamais venu à l'esprit d'Ignace Bourget de combattre le regroupement de catholiques d'ethnies différentes dans une même institution. Pourquoi Thério écrit-il alors ces mots qui n'ont aucun sens ? L'évêque lutte plutôt contre la mixité confessionnelle qu'il perçoit comme une menace à la fois religieuse et nationale.

Une pareille confusion entoure le traitement de la question des livres prohibés. Suivant fidèlement en cela la ligne qu'expose L.-A. Dessaulles dans son discours (pp. 58-61), le présentateur veut nous faire croire que, à l'époque, les règles de l'Index n'avaient pas cours au Québec (p. 16) et que, de toute manière, personne ne les respectait. Il affirme gratuitement « qu'un grand nombre de curés avaient probablement encore en leur possession Les paroles d'un croyant de La Mennais » (p. 18). Quant à lui, l'archevêque de Québec, CharlesFrançois Baillargeon, n'aurait fait aucun cas des livres interdits que renfermait la bibliothèque de l'Institut canadien de sa ville (p. 25). Que faut-il alors penser des directives explicites qu'ont approuvées à l'unanimité les évêques du Québec au concile provincial de 1854, excluant des sacrements les membres d'instituts littéraires qui possédaient des livres contraires à la foi et aux mœurs ? Ou bien de la déclaration on ne peut plus limpide provenant du Saint-Office en 1867 voulant que les règles de l'Index étaient «strictement obligatoires " au Canada? Dura lex sed lex.

La présentation reflète en effet le même manque de lucidité qui anime la pensée et l'action de L.-A. Dessaulles à l'Institut canadien. Car, en définitive, quel objectif ce personnage qui se définit toujours comme un catholique poursuit-il ? Qu'entend-il donc par l'affirmation que « l'Église doit être dans l'État»? Lors des pourparlers entamés avec Ignace Bourget autour de la question de la bibliothèque, quel but sa 
proposition de placer les livres interdits dans une section à part vise-t-elle? Plus apparente que réelle, cette solution conserve en effet à chaque membre l'accès intégral à ces volumes. Et puis, si cette question est essentiellement individuelle et relève des affaires internes de l'Institut (p. 61), pourquoi L.-A. Dessaulles s'engage-t-il dans des discussions avec l'évêque à qui il nie tout droit d'intervention ?

On assiste au même jeu de cache-cache lorsqu'il insiste que son appel au Saint-Siège contre la condamnation de l'évêque n'est pas fait au nom de l'Institut, mais uniquement de ses membres catholiques. Cette subtile distinction enlève à Rome toute possibilité de médiation, rôle qu'elle s'était pourtant montrée prête à assumer. Pourquoi, par la suite, choisit-il délibérément de saborder cet appel en prononçant trois conférences controversées qui ont l'effet de lui aliéner toute sympathie de la part des autorités romaines ? Croyait-il vraiment à cet appel dès le départ? Quoi qu'il en soit, c'est un drôle de laïc qui accepte un évêque comme interlocuteur valable dans la question de la bibliothèque, qui a recours au Saint-Siège pour se mettre à l'abri de l'arbitraire épiscopal, et qui enfin demande aux tribunaux d'accorder la sépulture ecclésiastique à un confrère laïc.

Qu'exige l'évêque Bourget sinon que L.-A. Dessaulles et ses collègues soient conséquents avec eux-mêmes ? S'ils sont catholiques, qu'ils adhèrent aux lois de l'Église. L'évêque s'inquiète surtout des jeunes qui, en leur qualité de membres de l'Institut ou d'externes abonnés à la bibliothèque, compromettent leur bien-être spirituel. À ses yeux, tous les membres, en versant leurs souscriptions à l'achat de livres et à l'abonnement de journaux, « concourent efficacement [à ce] mal » (p. 85) qui est bien collectif et non individuel. Toutefois, dans sa directive de 1858 privant les récalcitrants des sacrements, l'évêque prend soin de ne pointer du doigt ni in- 
dividu ni institution afin d'éviter tout embarras public. Dans le même esprit, il ne s'arroge pas le pouvoir exclusif d'absoudre les excommuniés. Si, par la suite, Ignace Bourget repousse l'accommodement qu'avance L.-A. Dessaulles, c'est que, de l'aveu même de celui-ci, la loi garantit toujours aux membres le plein accès à la bibliothèque parce qu'ils en sont les propriétaires communs (pp. 87, 95). L'évêque a-t-il tort de voir dans cette proposition une manœuvre qui porte atteinte à son autorité et à celle du Saint-Siège ? Lorsque, en 1867, l'Institut lance un appel public aux protestants pour l'aider à sortir d'une crise financière qu'il impute aux agissements du clergé catholique, Ignace Bourget est encore plus outré (p. 80). Des membres de la French Canadian Missionary Society, que de riches angloprotestants de Montréal avaient fondée dans le but de convertir les Canadiens français, répondent à l'appel lors d'une réunion qui se tient exclusivement en anglais. S'étonnera-ton si, dix ans après avoir soulevé un problème demeuré sans solution, l'évêque réclame de la part de Rome une condamnation publique de l'Institut?

Il y a, à n'en pas douter, quelque chose de noble et de séduisant dans la passion pour l'universalisme, pour la solidarité humaine et pour la libre expression qu'énonce L.-A. Dessaulles dans son discours sur la tolérance. Toutefois, la confusion du laïc et du religieux y est maintenue. Dans sa forme, la conférence se lit comme un mandement truffé de références et de citations aux Écritures saintes, aux Pères de l'Église et à des ecclésiastiques contemporains, sur l'autorité desquels L.-A. Dessaulles, tel un évêque, appuie ses affirmations. Dans son contenu, elle est une longue homélie sur la charité chrétienne dont se sert le polémiste pour faire la leçon aux autorités religieuses. Aussi, exprime-t-elle toute la foi, toute la naïveté et la suffisance d'un vrai croyant, c'est-à-dire du libéral à l'endroit de son siècle « qui a plus fait pour l'avance- 
ment de l'humanité que tous les autres ensemble». Le dixneuvième siècle aurait "fait disparaittre les castes ", «irrévocablement substitué le principe de la persuasion à celui de la contrainte » et « l'esprit de fraternité à celui de la rivalité hostile » (p. 32).

Cette idolâtrie du siècle se double d'une absence de vision lucide de la réalité sociopolitique canadienne à l'époque de l'Union et de la Confédération. L.-A. Dessaulles croit que l'entêtement que manifestent l'évêque et ses acolytes à soutenir les distinctions religieuses entrave la fraternité entre les hommes de nationalités et confessions différentes: "Dans un pays mixte, où est le mal que les esprits bien faits appartenant aux diverses sectes chrétiennes se donnent mutuellement le baiser de la paix sur le champ de la science » (p. 31) ? L'intolérance aurait provoqué des ravages incalculables, dont l'émigration d'un demi-million de compatriotes aux États-Unis n'est pas le moindre! (p. 52)

Pourtant, le Canada était-il à l'époque un pays de bonne entente perturbé par une coterie de réactionnaires catholiques? Comment expliquer alors la visite au Canada du prédicateur antipapal, Alessandro Gavazzi, en 1853 et les émeutes interconfessionnelles qu'elle a causées ? Et l'Ordre d'Orange, qui prenait son envol à ce moment, et la French Canadian Missionary Society, que subventionnait grassement l'élite angloprotestante du Québec, faisaient-ils œuvre de compréhension mutuelle ? S'il est vrai que la religion troublait la paix sociale au Canada, il n'en reste pas moins que L.-A. Dessaulles ne va pas à la racine du mal lorsqu'il blâme le seul Ignace Bourget d'un phénomène qui dépasse largement son pouvoir et son influence. Le polémiste n'est surtout pas sensible à l'aspiration d'hégémonie anglo-protestante qui se manifeste avec toujours plus d'ardeur dans toutes les colonies anglophones de l'Amérique du Nord britannique et qui ne présagera rien de 
bon pour les catholiques après la Confédération. C'est précisément dans ce contexte crucial que L.-A. Dessaulles propose de retirer à l'Église toute son autonomie, tout pouvoir d'action efficace et de mobilisation dans la société. Car en dernier ressort, l'objectif du pamphlétaire libéral n'est pas la séparation de l'Église et de l'État, mais bien la transformation de l'Église en une simple succursale de l'État qui, il vaut la peine de le rappeler, est entre les mains d'une majorité protestante.

Le promoteur contemporain de L.-A. Dessaulles, Thério, quant à lui, nourrit le mythe de la grande noirceur en regrettant la déchéance de ces "grands intellectuels", de ces «savants » et de cette université laïque, tous destinés à un avenir si prometteur. Quoi qu'il en soit, une société coloniale de moins d'un million d'habitants francophones pouvait-elle receler autant de génies ? L.-A. Dessaulles possédait bien sûr une intelligence vive, un esprit curieux et des enthousiasmes multiples. Avait-il, cependant, la discipline intellectuelle qui lui aurait permis de poursuivre un projet, de réaliser une œuvre, dans une branche du savoir de son choix ? Avant la déconfiture de l'Institut canadien, n'avait-il produit que des éditoriaux, des pamphlets et des conférences? Avait-il les moyens de consacrer une partie de sa vie professionnelle à l'enseignement supérieur? La désastreuse gestion de ses affaires fournit une réponse on ne peut plus claire à cette question. D'autre part, ses collègues avaient-ils les ressources matérielles et spirituelles non seulement pour établir une université, mais la maintenir? Car une université est bien plus qu'une faculté de droit qui, sous la tutelle de l'Institut canadien, n'a duré que quelques brèves années. Ne faudrait-il pas convenir que, en dehors des communautés religieuses (et encore!), les spécialistes dans les domaines du savoir brillaient par leur absence et que, même s'ils avaient existé, les moyens de les faire vivre 
manquaient ? Ne faudrait-il pas aborder cette question avec un sens de juste proportion et se départir des illusions de grandeur à propos des capacités de la société québécoise d'alors ?

Il y a un peu plus d'un quart de siècle, Thério écrivait ceci au sujet de l'évêque Bourget: "[II] a canalisé toutes les ressources, toutes les énergies spirituelles et nationales, les a pliées à sa façon de penser et d'agir, leur a donné une forme qui s'est perpétuée à travers le temps et qui nous rejoint... C'est lui qui a indiqué le chemin à tout un peuple » (Ignace Bourget écrivain, 1975, p. 40). Dans son plus récent opuscule, le littérateur, tout en condamnant le parti pris politique, l'absence d'esprit démocratique et la servilité de l'épiscopat, refuse à deux reprises (notes pp. 48, 56) de signaler qu'Ignace Bourget était le seul évêque ayant refusé de rédiger un mandement favorable à la Confédération. Comment expliquer ce silence et, encore plus, ce revirement face à ce qu'il avait écrit précédemment ? Est-il nécessaire aujourd'hui de dépeindre l'évêque tout en noir et ses opposants tout en blanc?

Roberto Perin

Collège Glendon

Université York.

\section{Jean-Pierre Boyer. Appel à la justice de l'État de Pierre du Calvet. Champion des droits démocratiques au Québec. Québec, Septentrion, 2002. 321 p.}

Quiconque s'intéresse à l'histoire des idées au Québec et, plus particulièrement, aux répercussions de l'invasion américaine (1775-1776) et à la circulation des idées démocratiques dans la "Province of Quebec ", trouvera son profit à 